\title{
Desnutrição neonatal e produção de IFN- $\gamma$, IL-12 e IL-10 por macrófagos/linfócitos: estudo da infecção celular, in vitro, por Staphylococcus aureus meticilina sensível e meticilina resistente ${ }^{1}$ \\ $N-\gamma$ (1)
}


608 | TB COSTA et al.

\section{Métodos}

Ratos machos Wistar foram amamentados por mães cuja dieta, durante a lactação, continha 17\% de proteína no grupo nutrido e $8 \%$ no grupo desnutrido. Após desmame, ambos os grupos receberam a dieta normoproteica. Os macrófagos foram obtidos após traqueostomia, através da coleta do lavado broncoalveolar. Para obtenção dos linfócitos, foi realizado o procedimento cirúrgico de punção cardíaca. Após o isolamento dos diferentes tipos celulares, procedeu-se à realização dos estímulos com as cepas de estudo. A dosagem das citocinas foi realizada pelo método de Enzyme-Linked Immunosorbent Assay, a partir de amostras coletadas do sobrenadante das culturas após 24 horas de incubação.

\section{Resultados}

A desnutrição acarretou diminuição do crescimento ponderal, redução na produção de Interferon gama em cultura de macrófagos alveolares e linfócitos e diminuição na produção de Interleucina-12 em cultura de macrófagos alveolares. Apenas a produção de Interferon gama e Interleucina-10 em cultura de macrófagos alveolares apresentou diferença entre as cepas analisadas, em ambos os grupos estudados.

\section{Conclusão}

O modelo de desnutrição neonatal produziu sequela no peso corporal e reduziu a produção de citocinas pró-inflamatórias (Interleucina-12 e Interferon gama), indicando que esse modelo de desnutrição pode comprometer a resolução de um processo infeccioso. A cepa de Staphylococcus aureus resistente à meticilina estimulou uma maior produção de Interferon gama e Interleucina-10 por macrófagos alveolares, o que sugeriu estimulação imunológica mais intensa, por essa cepa, nesse tipo celular especificamente.

Termos de indexação: Citocinas. Desnutrição. Linfócitos. Macrófagos. Meticilina. Staphylococcus aureus.

\section{A B S T R A C T}

\section{Objective}

The present study assessed the influence of neonatal malnutrition on the production of interferon gamma, interleukin-12 and interleukin-10 in cultured macrophages and lymphocytes infected in vitro with methicillin-sensitive or methicillin-resistant Staphylococcus aureus.

\section{Methods}

Male Wistar rats were suckled by mothers fed during lactation a chow containing 17\% protein for the nourished group and $8 \%$ for the undernourished group. After weaning, both groups received a normal diet in terms of protein content. The macrophages were obtained by bronchoalveolar lavage after tracheostomy. Cardiac puncture was used for the collection of lymphocytes. After isolation of different cell types, the challenge with the different strains was performed. Cytokines were measured by enzyme-linked immunosorbent assay (ELISA), using samples collected from the culture supernatant after an incubation period of 24 hours.

\section{Results}

Malnutrition let to slow weight gain, low interferon gamma in cultured alveolar macrophages and lymphocytes and low production of interleukin-12 in cultured alveolar macrophages. Only interferon gamma and interleukin-10 in cultured alveolar macrophages differed between the two groups and study strains.

\section{Conclusion}

The neonatal malnutrition model used impaired weight gain and reduced production of proinflammatory cytokines (interleukin-12 and interferon gamma), indicating that protein malnutrition may result in an inability to fight infections. The methicillin-resistant Staphylococcus aureus strain stimulated macrophages to produce interferon gamma and interleukin-10, suggesting that this strain better provokes the immune system, specifically for this cell type.

Indexing terms: Cytokines. Malnutrition. Lymphocytes. Macrophages. Methicillin. Staphylococcus aureus.

\section{N T R O D U ÇÃ O}

O processo de desnutrição é caracterizado por um desequilíbrio e/ou uma deficiência de nutrientes no organismo ${ }^{1}$. A nutrição deficiente no período crítico de gestação e maturação neonatal enfraquece o desenvolvimento e a diferenciação do sistema imune². Em humanos, even- 
tos importantes para a imunocompetência são iniciados ainda no embrião e continuam na primeira semana de vida. Em ratos, a competência imunológica também é adquirida gradualmente após o nascimento ${ }^{3}$. Nesse sentido, os efeitos da desnutrição são mais intensos e permanentes quanto mais precocemente ocorrer a agressão e mais tarde for iniciada a reabilitação nutricional' ${ }^{1}$.

Células de extrema importância no controle e na resolução dos processos infecciosos, os macrófagos encontram-se em número reduzido e têm muitas das suas funções comprometidas em animais desnutridos ${ }^{4}$. No pulmão, essas células de defesa possuem papel central na manutenção da estrutura normal desse órgão e são de grande importância para a defesa contra microrganismos que comumente infectam o homem através das vias respiratórias ${ }^{5}$. Esses fagócitos atuam como células acessórias para os linfócitos e, em resposta à infecção, liberam um grupo estruturalmente diferenciado de moléculas que incluem: Interleucina-1 (IL-1), IL-10, IL-12, Fator de Necrose Tumoral alfa (TNF- $\alpha$ ), dentre outras ${ }^{6}$.

As citocinas desempenham um papel determinante no complexo nutrição-infecção. Esses peptídeos atuam como sinalizadores que direcionam o desenvolvimento da imunidade adaptativa com geração de linfócitos $T$ específicos em resposta a um agente infeccioso ${ }^{7}$. Nesse contexto, fatores nutricionais podem modificar o curso da resposta imune por interferir na síntese, liberação e responsividade das citocinas sobre tecidos-alvos.

A relação de causalidade entre desnutrição, supressão imunológica e infecção tem sido alvo frequente de pesquisas ${ }^{9}$. Dados epidemiológicos revelam que a relação da deficiência nutricional com maior mortalidade se deve ao fato de ela aumentar a susceptibilidade aos agentes infecciosos e também à gravidade dessas infecções ${ }^{10}$. No Brasil, o Staphylococcus aureus é uma das bactérias mais frequentemente isoladas em infecções hospitalares. Trata-se de um microorganismo que apresenta fatores de virulência, além de diversos mecanismos de resistência às drogas antimicrobianas ${ }^{11}$.
O uso indiscriminado da meticilina e de outras penicilinas semissintéticas na década de 1960 permitiu a emergência do Staphylococcus aureus Meticilina Resistente (MRSA), que tem se tornado o mais importante patógeno nosocomial em todo o mundo, capaz de causar uma ampla variedade de infecções ${ }^{12}$. Estudos sugerem que, além de impor limitações terapêuticas, fatores intrínsecos do MRSA não relacionados à resistência às drogas antimicrobianas podem influenciar na sua virulência ${ }^{13,14}$. Porém, ainda há muito a ser esclarecido no que diz respeito à gravidade dos quadros infecciosos que envolvem esse microrganismo.

Embora diferentes estudos demonstrem, tanto em modelos experimentais quanto em seres humanos, que a desnutrição diminui a eficácia da resposta imune e consequentemente aumenta a susceptibilidade à infecções ${ }^{15}$, são escassos os trabalhos que analisam o efeito da desnutrição neonatal sobre a funcionalidade de células imunes em quadros infecciosos que envolvem microrganismos resistentes a antibióticos. Dessa forma, o presente estudo teve como objetivo avaliar as repercussões desse modelo de desnutrição sobre o comportamento de citocinas produzidas por macrófagos e linfócitos após processo de infecção celular, in vitro, analisando possíveis diferenças entre cepas sensíveis e resistentes à meticilina, no que diz respeito à liberação de citocinas por essas células de defesa.

\section{MÉ T O D OS}

Foram utilizados 48 ratos machos, albinos, da linhagem Wistar (89-120 dias), provenientes da colônia do biotério do departamento de nutrição da Universidade Federal de Pernambuco. Os animais foram mantidos em temperatura controlada (Média- $\mathrm{M}=22$, Erro-Padrão- $\mathrm{EP}=1^{\circ} \mathrm{C}$ ), com ciclo fotoperiódico de claro-escuro de 12 horas e com livre acesso à água e à ração. Os experimentos foram baseados nas recomendações éticas do Colégio Brasileiro de Experimentação 
Animal (COBEA) e do National Institute of Health Guide for Care and Use of Laboratory Animals, e previamente aprovados pela Comissão de Ética em Experimentação Animal do Centro de Ciências Biológicas da Universidade Federal de Pernambuco (CEEA-UFPE), Processo n 23076.026681/ 2009-02.

Durante todo o período de gestação, as mães receberam a dieta com $23 \%$ de proteína (Labina-Purina ${ }^{\circledR}$ do Brasil). Um dia após o nascimento, a ninhada foi padronizada em seis filhotes machos por mãe. Nesse mesmo dia, adotado como o primeiro dia de vida do animal, as ninhadas foram divididas em dois grupos: nutrido - constituído por filhotes amamentados por mães submetidas à dieta contendo $17 \%$ de proteína à base de caseína utilizada como fonte proteica (AIN93G), e desnutrido - constituído por filhotes amamentados por mães submetidas à dieta contendo $8 \%$ de proteína à base de caseína utilizada como fonte proteica (AIN93G). Após o desmame $\left(22^{\circ} \mathrm{dia}\right)$, os animais foram separados de suas mães e passaram a receber dieta com $23 \%$ de proteína (Labina-Purina ${ }^{\circledR}$ do Brasil) até o final do experimento.

Durante o período de aleitamento, os pesos corporais de cada animal foram registrados diariamente (em balança eletrônica digital Marte ${ }^{\circledR}$, modelo S-4000-com sensibilidade de $0,1 \mathrm{~g}$ ), a fim de se fazer o acompanhamento do peso corporal durante a manipulação nutricional. A partir do $22^{\circ}$ dia de vida até o final do experimento, a pesagem foi realizada em dias alternados, objetivando acompanhar a reposição nutricional dos animais.

\section{Cepas de staphylococcus aureus}

Após levantamento bibliográfico em busca de cepas de referência segundo o The American Type Culture Collection (ATCC), foram selecionadas as cepas MRSA (ATCC 33591) e Staphylococcus aureus Metilicina Sensível (MSSA) (ATCC 29213) devido ao seu perfil distinto de resistência. As duas cepas bacterianas acima citadas foram obtidas junto ao Instituto de Micro- biologia Prof. Paulo de Góes, Departamento de Microbiologia Médica da Universidade Federal do Rio de Janeiro, sendo mantidas em caldo Tryptic Soy Broth (TSB), com adição de $20 \%$ de glicerol, em câmara $-80^{\circ} \mathrm{C}$, até sua utilização.

Vinte e quatro horas antes de cada experimento, as cepas foram semeadas em placas de ágar sangue (ágar suplementado com sangue de carneiro a $5 \%$ ) e incubadas em estufa a $37^{\circ} \mathrm{C}$. No início do ensaio, algumas colônias foram transferidas para tubos com tampão fosfato/salina (Phosphate-Buffered Saline - PBS), estéreis, de forma a se obter, com auxílio de espectrofotômetro a 570nm, uma turbidez de aproximadamente $0,15 \mathrm{~nm}$. Essa absorbância, segundo trabalho desenvolvido por Lu \& McEwan ${ }^{16}$, corresponde aproximadamente à concentração de $10^{6} \mathrm{UFC} / \mathrm{mL}$ de PBS.

\section{Lavado broncoalveolar}

O Lavado Broncoalveolar (LBA) foi obtido de acordo com a técnica utilizada por De Castro et al. ${ }^{17}$. Para isso, os animais foram anestesiados com uretana $12,5 \%$ na proporção de $8 \mathrm{~mL} / \mathrm{kg}$ administrado por via interperitonial. O LBA foi coletado após a introdução de salina a 0,9\% através de uma cânula plástica inserida na traqueia, e, em seguida, aspirada em várias alíquotas de $3 \mathrm{~mL}$, coletadas em tubos cônicos de polipropileno de $50 \mathrm{~mL}$ (Falcon ${ }^{\circledR}$, Sigma ${ }^{\circledR}$ ). Recuperaram-se aproximadamente $30 \mathrm{~mL}$ de LBA para cada animal.

Para a cultura de macrófagos alveolares, centrifugaram-se amostras do LBA a 1.500rpm durante 15 minutos. O precipitado que corresponde às células foi ressuspendido em meio de cultura RPMI 1.640 (Gibco ${ }^{\circledR}$-Invitrogen Corporation) e suplementado com $3 \%$ de soro bovino fetal $\left(\mathrm{Gibco}^{{ }_{-}}\right.$ Invitrogen Corporation). As células, contadas com o auxílio do corante azul de tripan, foram transferidas para placas de cultura de 6 poços com $35 \mathrm{~mm}$ de diâmetro cada um (Falcon ${ }^{\circledR}$ ), em uma proporção de $10^{6}$ células $/ \mathrm{mL}$ de RPMI 1.640 em cada poço. Após uma hora na incubadora a $37^{\circ} \mathrm{C}$ e $5 \% \mathrm{CO}_{2}$, desprezou-se o sobrenadante com as células não aderentes e adicionou-se RPMI, 
deixando-se as placas por mais uma hora em incubadora para estabilização das células.

Após o período de estabilização das células, foram especificados 4 sistemas $(n=24)$ : Controle negativo (C-), composto por macrófagos em cultura (1 mL/poço contendo $10^{6}$ macrófagos/ $\mathrm{mL}$ de RPMI 1.640); Controle positivo ( $\mathrm{C}+$ ), semeIhante ao anterior, adicionado de 10 $\mathrm{LL}$ de LPS (sorotipo de Escherichia coli; 055:B5, Sigma ${ }^{\circledR}$ ); e dois sistemas-teste, MSSA (ATCC 29213), composto por macrófagos em cultura, adicionados dessa cepa, na proporção de $10^{6} \mathrm{UFC} / 10^{6}$ de macrófagos/mL de RPMI 1.640, e MRSA (ATCC 33591), com composição semelhante, diferindo apenas quanto à cepa adicionada.

\section{Punção cardíaca}

Sob efeito do anestésico uretana 12,5\%, na proporção de $8 \mathrm{~mL} / \mathrm{kg}$, administrado por via intraperitoneal, o animal foi posicionado em decúbito dorsal sobre superfície plana e estéril. Realizou-se a antissepsia da região torácica, e procedeu-se em seguida à toracotomia. Exposto o coração, cerca de 3-5mL de sangue foram aspirados por punção cardíaca, utilizando-se uma seringa de $5 \mathrm{~mL}$ e agulha $0,70 \times 25$ 22G1 (BD Biosciences ${ }^{\circledR}$ ). Depois de desacoplar a agulha da extremidade da seringa, o volume sanguíneo coletado foi imediatamente transferido para tubo contendo anticoagulante Etileno-Diaminotetraacetato (EDTA) $15 \%$.

Para a cultura de linfócitos, o sangue obtido a partir da punção cardíaca foi diluído em meio de cultura RPMI 1.640 ( $5 \mathrm{~mL}$ de sangue + $5 \mathrm{~mL}$ de RPMI 1.640). Aos $10 \mathrm{~mL}$ da suspensão resultante, foram adicionados $5 \mathrm{~mL}$ de histopaque (1 077-SIGMA), centrifugados a 1.500 rpm/30min. Após a centrifugação, a camada formada pelas células mononucleares foi aspirada e transferida para um segundo tubo, ao qual foram adicionados $10 \mathrm{~mL}$ de meio de cultura RPMI 1.640 e centrifugados por 10 minutos. nas mesmas condições anteriores. O sobrenadante foi desprezado e as células do sedimento resultante foram ressuspendidas em $1 \mathrm{~mL}$ de meio de cultura e contadas com o auxílio do corante azul tripan. A concentração foi ajustada para $1 \times 10^{6}$ células para cada $1 \mathrm{~mL}$ de meio de cultura, sendo disposto $1 \mathrm{~mL}$ em cada poço de placas tipo Falcon ${ }^{\circledR}$, que foram mantidas em incubadora durante uma hora a $37^{\circ} \mathrm{C}$ em atmosfera úmida com $5 \% \mathrm{CO}_{2}$.

Decorrido esse intervalo de tempo, o sobrenadante das placas de culturas contendo os linfócitos foi transferido para novos tubos e centrifugado a $1.500 \mathrm{rpm} / 10 \mathrm{mim}$. Esses tubos tiveram então seu sobrenadante desprezado, e o precipitado, correspondente aos linfócitos, ressuspendido em $1 \mathrm{~mL}$ de meio de cultura RPMI 1.640, e após nova contagem com o corante azul de tripan e novo ajuste no número de células, a cultura foi dispensada em novas placas tipo falcon de seis poços, procedendo-se então aos diferentes estímulos.

Foram formados quatro sistemas in vitro $(n=12)$ : $C^{-}$, composto por linfócitos em cultura ( $1 \mathrm{~mL} /$ poço contendo $10^{5}$ linfócitos $/ \mathrm{mL}$ de RPMI 1.640); $\mathrm{C}^{+}$, semelhante ao anterior, adicionado de $10 \mu \mathrm{L}$ de LPS; e dois sistemas-teste: MSSA (ATCC 29 213), composto por linfócitos em cultura, adicionados dessa cepa, na proporção de $10^{6} \mathrm{UFC} / 10^{5}$ de linfócitos/mL de RPMI 1 640; e MRSA (ATCC 33 591), com composição semelhante, diferindo apenas quanto à cepa adicionada.

A dosagem de IFN- $\gamma$, IL-12 e IL-10 por macrófagos alveolares e linfócitos em cultura foi realizada pelo método de Enzyme-Linked Immunosorbent Assay (ELISA), por meio do kit Quantikine ${ }^{\circledR}, R \& D$ Systems. As amostras foram coletadas a partir do sobrenadante da cultura de macrófagos alveolares e linfócitos após um período de 24 horas de incubação.

Na comparação entre os grupos, utilizou-se o teste $t$ de Student para os dados paramétricos e o teste de Mann-Whitney para os dados não paramétricos. Os resultados foram representados em $M$ e EP. A significância foi definida para $p<0,05$. 


\section{RES U L T A D O $S^{(5)}$}

Nos primeiros dias de vida, os pesos corporais (g) do grupo Nutrido (N) e Desnutrido (DN) foram semelhantes até $03^{\circ}$ dia. A partir do $4^{\circ}$ dia, até o $21^{\circ}$ dia pós-natal, os valores dos pesos corporais dos animais desnutridos foram menores $(p=<0,001)$ em relação aos dos animais nutridos. Entre o $23^{\circ}$ e o $89^{\circ}$ dia de vida, período em que ocorreu a reposição nutricional, os valores dos pesos do grupo desnutrido permaneceram menores $(p=<0,001)$ quando comparados aos do grupo nutrido (Figura 1).

A análise intergrupos dos níveis de Interferon gama (IFN- $\gamma$ ), em cultura de macrófagos alveolares demonstra valores menores dessa citocina no grupo de animais desnutridos quando comparados ao grupo nutrido, para os sistemas C+ e MRSA. No entanto, não foi observada diferença significativa entre os referidos grupos para os sistemas C- e MSSA. No que diz respeito à análise intragrupo, foi evidenciado o mesmo padrão de resposta para o grupo nutrido e desnutrido: o sistema MRSA apresentou níveis maiores de IFN- $\gamma$ quando comparado ao respectivo MSSA (Tabela 1).

A dosagem de IFN- $\gamma$ em cultura de linfócitos revelou níveis menores dessa citocina no grupo de animais desnutridos quando comparado ao grupo nutrido em todos os sistemas analisados. No que diz respeito à análise intragrupo, não foi observada diferença significativa entre os sistemas-teste, MSSA e MRSA, tanto em grupos de animais nutridos como desnutridos (Tabela 1).

A análise intergrupos dos níveis de IL-12 em cultura de macrófagos alveolares apresenta valores menores dessa citocina em animais do grupo desnutrido quando comparado ao nutrido em todos os sistemas analisados. No que diz respeito à análise intragrupo, não foi observada diferença significativa entre os sistemas-teste,

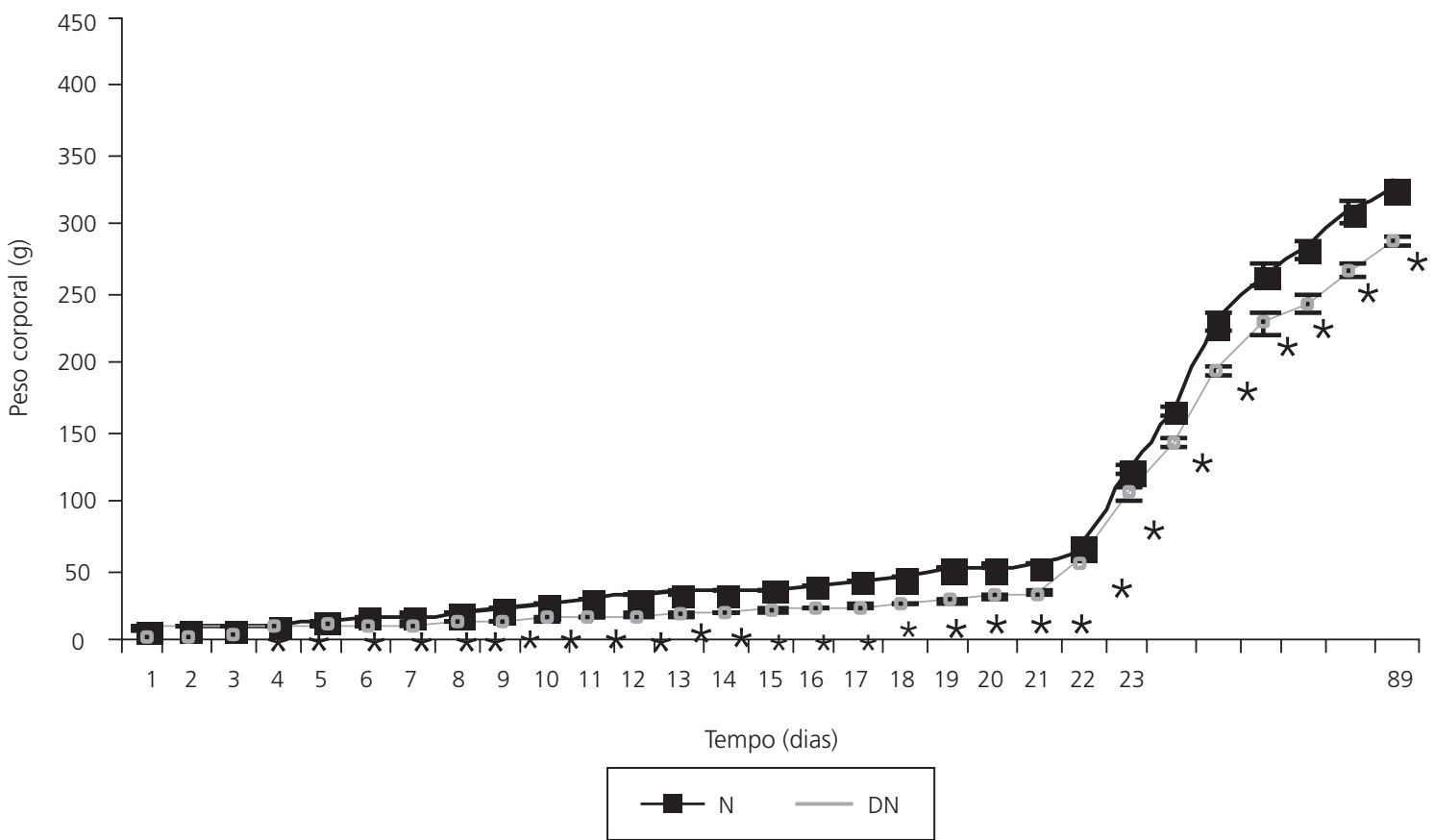

Figura 1. Evolução da curva ponderal durante a desnutrição neonatal (21 dias) e reposição nutricional (23-89 dias) dos grupos Nutrido (N) e Desnutrido (DN). Dados expressos em Média (M), Erro-Padrão (EP) para 24 animais. Recife, PE, 2011.

Nota: " $p<0,05$ na comparação N e DN.

5 No que diz respeito às comparações intragrupo para os $\mathrm{C}^{+}$e $\mathrm{C}^{-}$, em ambas as culturas celulares analisadas, o sistema $\mathrm{C}^{+}$ apresentou níveis maiores de IFN- $\gamma$, IL-12 e IL-10 quando comparado ao respectivo C . 
MSSA e MRSA, tanto em grupos de animais nutridos como desnutridos (Tabela 2).

Os níveis de IL-12 em sobrenadante de cultura de linfócitos não apresentaram diferença significativa entre grupos de animais nutridos e desnutridos em nenhum dos sistemas analisados.
No que diz respeito à análise intragrupo, não foi observada diferença significativa entre os sistemas-teste, MSSA e MRSA, tanto em grupos de animais nutridos como desnutridos (Tabela 2).

Na análise intergrupos dos níveis de IL-10 em cultura de macrófagos alveolares não foi

Tabela 1. Dosagem de INF- $\gamma$ em sobrenadante de cultura de macrófagos ( $n=24)$ e linfócitos ( $n=12)$. Recife (PE), 2011.

\begin{tabular}{|c|c|c|c|c|c|c|}
\hline \multirow{2}{*}{ Células } & \multirow{2}{*}{ Sistemas } & \multicolumn{2}{|c|}{ Nutrido } & \multicolumn{2}{|c|}{ Desnutrido } & \multirow{2}{*}{ Valor de $p$} \\
\hline & & $M$ & EP & M & $E P$ & \\
\hline \multirow[t]{3}{*}{ Macrófagos alveolares } & $\mathrm{C}^{-}$ & 142,75 & 13,80 & 143,47 & 1,11 & 0,707 \\
\hline & $\mathrm{C}^{+}$ & 213,59 & 9,75 & 156,35 & 1,70 & $<0,001^{a}$ \\
\hline & Valor de $p$ & \multicolumn{2}{|c|}{$<0,001^{b}$} & \multicolumn{2}{|c|}{$<0,001^{b}$} & \\
\hline \multirow[t]{5}{*}{ Linfócitos } & Valor de $p$ & \multicolumn{2}{|c|}{$<0,001^{b}$} & \multicolumn{2}{|c|}{$<0,001^{b}$} & \\
\hline & $C^{-}$ & 259,59 & 4,32 & 235,69 & 3,02 & $0,001^{a}$ \\
\hline & $\mathrm{C}^{+}$ & 294,01 & 7,99 & 253,85 & 4,09 & $0,001^{\mathrm{a}}$ \\
\hline & Valor de $p$ & \multicolumn{2}{|c|}{$0,004^{\mathbf{b}}$} & \multicolumn{2}{|c|}{$0,005^{b}$} & \\
\hline & Valor de $p$ & \multicolumn{2}{|c|}{0,828} & \multicolumn{2}{|c|}{0,485} & \\
\hline
\end{tabular}

Os resultados são representados em Média (M), Erro-Padrão(EP). pg/mL.

Representação dos sistemas: $C^{-}$: Controle Negativo; $C^{+}$: Controle Positivo; MSSA: Staphylococcus aureus Metilicina Sensível; MRSA: Staphylococcus aureus Metilicina Resistente.

Letras minúsculas indicam diferença significativa $(p<0,05)$ na comparação; ${ }^{a}$ intergrupos; ${ }^{\text {bintragrupo. }}$

Tabela 2. Dosagem de IL-12 em sobrenadante de cultura de macrófagos ( $n=24)$ e linfócitos ( $n=12)$. Recife (PE), 2011.

\begin{tabular}{|c|c|c|c|c|c|c|}
\hline \multirow{2}{*}{ Células } & \multirow{2}{*}{ Sistemas } & \multicolumn{2}{|c|}{ Nutrido } & \multicolumn{2}{|c|}{ Desnutrido } & \multirow{2}{*}{ Valor de $p$} \\
\hline & & $M$ & $E P$ & $M$ & $E P$ & \\
\hline \multirow[t]{5}{*}{ Macrófagos alveolares } & $\mathrm{C}^{-}$ & 126,74 & 4,65 & 116,10 & 1,59 & $0,006^{a}$ \\
\hline & $\mathrm{C}^{+}$ & 144,44 & 4,58 & 127,80 & 1,52 & $0,009^{a}$ \\
\hline & Valor de $p$ & \multicolumn{2}{|c|}{$<0,013^{b}$} & \multicolumn{2}{|c|}{$<0,001^{b}$} & \\
\hline & MSSA & 147,73 & 4,18 & 126,74 & 1,36 & $<0,001^{a}$ \\
\hline & MRSA & 139,47 & 2,54 & 124,22 & 1,55 & $<0,001^{a}$ \\
\hline \multirow[t]{7}{*}{ Linfócitos } & Valor de $p$ & \multicolumn{2}{|c|}{$<0,106$} & \multicolumn{2}{|c|}{0,235} & \\
\hline & $\mathrm{C}^{-}$ & 317,89 & 5,92 & 314,38 & 3,23 & 0,614 \\
\hline & $\mathrm{C}^{+}$ & 363,50 & 19,00 & 368,77 & 11,90 & 0,485 \\
\hline & Valor de $p$ & \multicolumn{2}{|c|}{$0,045^{b}$} & \multicolumn{2}{|c|}{$0,001^{b}$} & \\
\hline & MSSA & 389,82 & 27,80 & 386,31 & 9,01 & 0,818 \\
\hline & MRSA & 412,63 & 38,10 & 367,89 & 1,16 & 0,699 \\
\hline & Valor de $p$ & \multicolumn{2}{|c|}{0,639} & \multicolumn{2}{|c|}{0,238} & \\
\hline
\end{tabular}

Os resultados são representados em Média (M), Erro-Padrão(EP). pg/mL.

Representação dos sistemas: C': Controle Negativo; C $C^{+}$: Controle Positivo; MSSA: Staphylococcus aureus Metilicina Sensível; MRSA: Staphylococcus aureus Metilicina Resistente.

Letras minúsculas indicam diferença significativa $(p<0,05)$ na comparação; ${ }^{\text {intergrupos; }}$ ' intragrupo. 
614 | TB COSTA et al.

Tabela 3. Dosagem de IL-10 em sobrenadante de cultura de macrófagos ( $n=24)$ e linfócitos ( $n=12)$. Recife (PE), 2011.

\begin{tabular}{|c|c|c|c|c|c|c|}
\hline \multirow{2}{*}{ Células } & \multirow{2}{*}{ Sistemas } & \multicolumn{2}{|c|}{ Nutrido } & \multicolumn{2}{|c|}{ Desnutrido } & \multirow{2}{*}{ Valor de $p$} \\
\hline & & M & EP & M & EP & \\
\hline \multirow{5}{*}{ Macrófagos alveolares } & $\mathrm{C}^{-}$ & 154,14 & 3,12 & 148,53 & 4,84 & 0,341 \\
\hline & $\mathrm{C}^{+}$ & 173,83 & 3,05 & 176,42 & 9,64 & 0,729 \\
\hline & Valor de $p$ & \multicolumn{2}{|c|}{$<0,001^{b}$} & \multicolumn{2}{|c|}{$0,017^{b}$} & \\
\hline & MSSA & 179,97 & 3,89 & 176,86 & 6,35 & 0,680 \\
\hline & MRSA & 198,17 & 4,00 & 197,66 & 6,87 & 0,908 \\
\hline \multirow[t]{7}{*}{ Linfócitos } & Valor de $p$ & \multicolumn{2}{|c|}{$<0,012^{b}$} & \multicolumn{2}{|c|}{$0,037^{b}$} & \\
\hline & $\mathrm{C}^{-}$ & 334,76 & 1,20 & 335,98 & 0,80 & 0,394 \\
\hline & $\mathrm{C}^{+}$ & 347,49 & 3,38 & 348,92 & 3,69 & 0,781 \\
\hline & Valor de $p$ & \multicolumn{2}{|c|}{$0,005^{b}$} & \multicolumn{2}{|c|}{$0,007^{b}$} & \\
\hline & MSSA & 365,60 & 7,57 & 370,57 & 2,10 & 0,937 \\
\hline & MRSA & 377,99 & 1,40 & 372,07 & 3,23 & 0,124 \\
\hline & Valor de $p$ & \multicolumn{2}{|c|}{0,485} & \multicolumn{2}{|c|}{0,706} & \\
\hline
\end{tabular}

Os resultados são representados em Média (M), Erro-Padrão(EP). pg/mL.

Representação dos sistemas: $C^{-}$: Controle Negativo; $C^{+}$: Controle Positivo; MSSA: Staphylococcus aureus Metilicina Sensível; MRSA: Staphylococcus aureus Metilicina Resistente.

Letras minúsculas indicam diferença significativa $(p<0,05)$ na comparação; ${ }^{\text {intergrupos; }}$ ' intragrupo.

observada diferença significativa entre animais nutridos e desnutridos em nenhum dos sistemas de analisados. No que diz respeito à análise intragrupo, foi evidenciado o mesmo padrão de resposta para o grupo nutrido e desnutrido, nos quais o sistema MRSA apresentou níveis maiores de IL-10 quando comparado ao respectivo MSSA (Tabela 3).

Os níveis de IL-10 em sobrenadante de cultura de linfócitos não apresentaram diferença significativa entre grupos de animais nutridos e desnutridos em nenhum dos sistemas analisados. No que diz respeito à análise intragrupo, não foi observada diferença significativa entre os sistemas-teste, MSSA e MRSA, tanto em grupos de animais nutridos como desnutridos (Tabela 3 ).

\section{I S C U S S Ã O}

Os dados do presente estudo revelam que, durante o período de lactação, o ganho de peso corporal foi menor no grupo desnutrido quando comparado ao grupo nutrido. Os resultados demonstram diferença significativa entre os grupos desde o quarto dia de vida pós-natal, sugerindo que a desnutrição imposta durante a lactação interferiu de forma negativa no ganho de peso dos animais. Esses dados assemelham-se aos obtidos por Porto et al. ${ }^{18} \mathrm{e}$ Melo et al. ${ }^{19}$, que utlizaram a mesma dieta e o mesmo modelo de desnutrição aplicado no presente estudo.

O baixo peso em animais desnutridos durante o período de lactação já foi descrito em estudos $^{4,20}$ que empregaram a Dieta Básica Regional (DBR), deficiente em todos os seus constituintes, como modelo experimental de desnutrição. Apesar dos diferentes modelos experimentais de restrição nutricional referenciados neste estudo, a deficiência de proteínas promovida pela dieta contendo caseína a $8 \%$ mostrou-se eficiente em causar a desnutrição. A dieta à base de caseína nessa porcentagem é caracterizada como hipoproteica e provoca alteração no teor proteico do leite de lactantes que a ingerem. Esse parece ser um fator determinante na gênese de seus efeitos deletérios observados na prole ${ }^{18}$.

A substituição pela dieta normoproteica a partir do desmame não foi eficaz em equilibrar a diferença de peso entre os animais desnutridos e os animais nutridos, constatando-se, no presente 
estudo, um deficit permanente no peso corporal do grupo de animais amamentados por mães submetidas à dieta hipoproteica durante a lactação. Esses dados corroboram os obtidos por Porto et al. ${ }^{18}$, que também encontraram redução do peso corporal, verificada, inclusive, até a idade adulta. De acordo com Guzmán-Silva et al. ${ }^{21}$, animais desnutridos durante o período pré- e pós-natal, ao serem alimentados com dieta adequada nutricionalmente, rapidamente melhoram seu peso, no entanto, o peso alcançado após o período de reposição nutricional é inferior ao dos animais-controle.

Os efeitos da desnutrição sobre as infecções podem ser analisados no hospedeiro, uma vez que a deficiência nutricional pode condicionar seu estado de susceptibilidade e/ou de resistência ao desenvolvimento do processo infeccioso ${ }^{22}$. Nas últimas décadas, o Staphylococcus aureus tem adquirido papel de destaque não só por ser um patógeno humano responsável por infecções superficiais e sistêmicas que atingem indivíduos em diferentes faixas etárias, como também pela multirresistência aos antimicrobianos ${ }^{23}$. Ainda não existem pesquisas que relacionem a desnutrição neonatal com a produção de citocinas por células de defesa infectadas, in vitro, com MRSA. A maioria dos estudos que analisam modelos de desnutrição não investiga as possíveis repercussões desse processo após um longo período de reposição nutricional; além disso, as pesquisas, usualmente, não envolvem microrganimos com perfil de resistência ${ }^{4,24,25}$. No presente estudo, foi analisada a produção de IFN- $\gamma$, IL-12 e IL-10 por macrófagos e linfócitos após infecção celular, in vitro, com cepas de Staphylococcus aureus reconhecidas pelo ATCC e com perfis distintos de sensibilidade e resistência à meticilina.

Na presente pesquisa, a análise dos níveis de IFN- $\gamma$ em cultura de macrófagos alveolares revela que apenas os sistemas estimulados com LPS e com a cepa resistente à meticilina apresentaram diferença entre grupos de animais nutridos e desnutridos, o que sugere que o processo de deficiência nutricional não altere de maneira uniforme a resposta imunológica a diferentes estímulos em um mesmo tipo celular. Esses resultados corroboram em parte aqueles obtidos por Ishikawa et al. ${ }^{26}$, os quais constataram diminuição na produção IFN- $\gamma$ em grupos de animais desnutridos quando comparados ao grupo de animais nutridos em cultura de células esplênicas estimuladas com LPS, mas não se observou diferença nesse mesmo ensaio em culturas estimuladas com concanavalina $A$. Corroborando os resultados da presente pesquisa, diferentes estudos têm demonstrado que a desnutrição resulta em diminuição dos níveis de IFN- $\gamma$ produzidos por células mononucleares $^{27,28}$.

No que diz respeito à produção de IFN- $\gamma$ por linfócitos, o modelo de desnutrição adotado ocasionou uma redução nos níveis dessa citocina em todos os sistemas de análise. Esse achado pode ser justificado pelos estudos de Nájera et al. ${ }^{29}$, que verificaram que tanto a estrutura quanto a função do timo encontram-se prejudicadas em condições de desnutrição e que, consequentemente, a resposta de linfócitos $T$ é reduzida. A depleção acentuada dos linfócitos $T$ associada à diminuição da produção de IL-2, ambas decorrentes da desnutrição proteica, podem contribuir para os baixos níveis de IFN- $\gamma$ observados em indivíduos nessa condição. Essa relação foi claramente evidenciada em um estudo que envolveu crianças desnutridas, no qual foi observada redução significativa nos níveis de citocinas do perfil Th1 (IL-2 e IFN- $\gamma)^{25}$. Corroborando esses achados, Fló et al. ${ }^{30}$ observaram que a desnutrição em ratos durante $\mathrm{o}$ aleitamento também promove alterações em linfócitos T e B.

O IFN- $\gamma$ é uma citocina chave no desenvolvimento da resposta imune Th1, que é necessária para eliminação de diferentes patógenos; além disso, essa citocina atua aumentando a ativação de monócitos/macrófagos e suas funções microbicidas efetoras. Assim, uma diminuição na produção dessa citocina poderia estar diretamente relacionada ao aumento da susceptibilidade à infecção em quadros de desnutrição 25 . 
De forma semelhante, a produção de IL-12 por macrófagos alveolares também foi comprometida pela desnutrição neonatal. Os dados obtidos neste trabalho demonstram que macrófagos alveolares de ratos desnutridos apresentam menor produção de IL-12 tanto nos sistemas-controle quanto em situação de estímulo bacteriano. Hughes et al. ${ }^{31}$ descreveram que a desnutrição severa diminui os níveis de IL-12 produzidos por células dendríticas. De acordo com Melo et al. ${ }^{4}$, a desnutrição reduz a imunidade em geral, e, sobretudo, provoca alterações no pulmão, comprometendo a função dos macrófagos alveolares. De Castro et al. ${ }^{17}$ observaram em seu estudo que desnutrição neonatal, mesmo após a reposição nutricional, acarreta no rato adulto sequela duradoura na atividade funcional do macrófago alveolar. Todos esses aspectos podem ter sido refletidos na redução da produção de IL-12 encontrada no presente trabalho, uma vez que essa citocina tem como principais fontes de sua produção os macrófagos ativados e as células dendríticas.

O modelo de desnutrição aplicado nesta pesquisa não alterou a produção de IL-12 por linfócitos tanto nos ensaios-controle como nos estimulados com as cepas em estudo. Os resultados do presente estudo divergem daqueles obtidos em outras pesquisas que envolvem processos de desnutrição, as quais relatam redução na produção de citocinas tanto em modelos experimentais como em estudos com humanos 24,25 . Entretanto, sabe-se que diferentes estados de desnutrição podem modular as defesas do hospedeiro contra um único patógeno em graus variados $^{32}$. Assim, podemos supor que uma mesma citocina pode ter sua produção comprometida em um tipo celular em particular, mas não em outro, potencialmente menos afetado pela desnutrição.

No que diz respeito à dosagem de IL-10, não foi encontrada diferença entre grupos de animais nutridos e submetidos à desnutrição neonatal em ambas as culturas celulares realizadas. Esses resultados assemelham-se aos obtidos por Hill et al. ${ }^{14}$, os quais também não verificaram alterações na produção de IL-10 por células mononucleares esplênicas em animais com deficit proteico e energético.

Fock et al..$^{33}$ constataram que animais desnutridos são capazes de produzir níveis maiores de IL-10 quando comparados com os do grupo de animais nutridos, após infecção com LPS. Acredita-se que esse resultado, discrepante em relação ao presente estudo, seja consequência de uma adaptação do organismo para manter a homeostase em resposta à injeção intraperitoneal de LPS, uma vez que se trata de um estudo in vivo, no qual as repercursões sistêmicas podem ser mais intensas.

No que diz respeito às possíveis diferenças entre cepas de Staphylococcus aureus sensíveis e resistentes à meticilina, o presente estudo constatou que apenas a produção de IFN- $\gamma$ e IL-10 em cultura de macrófagos alveolares diferiu significativamente entre as cepas analisadas. Tendo em vista a ação biológica da IL-10, poderíamos sugerir que os altos níveis dessa citocina induzidos pela cepa resistente à meticilina caracterizariam um mecanismo de escape do MRSA, o qual permitiria sua sobrevivência por mais tempo no hospedeiro, visto que a IL-10 atuaria anulando a ação de citocinas pró-inflamatórias, capazes de intensificar o potencial microbicida de importantes células de defesa como os macrófagos. Entretanto, os altos níveis de IFN- $\gamma$ observados revelam questões conflitantes a respeito da resposta imune diante da cepa resistente à meticilina, as quais poderiam ser elucidadas através da realização de uma cinética de produção dessas citocinas, avaliando-se, assim, picos distintos de produção desses mediadores por um período superior a 24 horas de incubação.

As demais comparações realizadas entre as cepas bacterianas segundo o perfil de sensibilidade/resistência à meticilina não revelaram diferença estatística. Esse achado correlaciona-se de maneira positiva com outros parâmetros da resposta imune analisados por Salgado et al..$^{13} \mathrm{e}$ Duckworth \& Jordens ${ }^{34}$, os quais não observaram 
diferença no potencial de aderência celular, bem como na função fagocítica de neutrófilos e monócitos quando comparados às cepas sensível e resistente à meticilina.

Estudos que comparam fatores de virulência entre as referidas cepas não constataram diferença significativa no que diz respeito à produção de $\alpha, \beta, \delta, \gamma$-hemolisinas ${ }^{35}$, além disso, outros autores sugerem que a capacidade de produzir toxinas independe do perfil de resistência à meticilina ${ }^{36}$. Dessa forma, apesar de muitos trabalhos associarem a infecção por MRSA a altos índices de morbidade e mortalidade ${ }^{37,38}$, ainda há muito a ser investigado no que diz respeito a sua potencialidade intrínseca em promover infecções de maior gravidade.

É importante ressaltar que, no presente estudo, houve um padrão de resposta no grupo nutrido e desnutrido no que diz respeito às comparações realizadas entre as cepas de MSSA e MRSA, e observou-se diferença estatística na análise das mesmas citocinas e culturas celulares, sugerindo que a desnutrição neonatal não atuou como fator modificador da relação entre produção de citocinas e perfil de resistência/sensibilidade a meticilina. Dessa forma, são necessárias investigações adicionais para se compreenderem melhor as possíveis alterações promovidas pela desnutrição em períodos considerados críticos para o desenvolvimento e suas eventuais repercussões sobre diferentes parâmetros da resposta imunológica diante das bactérias de importância hospitalar como MRSA.

\section{O N CLUSÃ O}

A desnutrição proteica imposta às ratas durante o período de aleitamento causou redução ponderal persistente nos filhotes. O modelo de desnutrição adotado promoveu uma redução na produção das citocinas IFN- $\gamma$ em cultura de macrófagos alveolares e linfócitos, e IL-12 em cultura de macrófagos alveolares, indicando que esse modelo de desnutrição pode comprometer a resolução de um processo infeccioso. A cepa de MRSA induziu uma maior produção das citocinas IFN- $\gamma$ e IL-10, sugerindo assim a possibilidade de uma estimulação imunológica mais intensa por parte desse patógeno no que diz respeito à cultura de macrófagos alveolares.

\section{COLABORADORES}

TB COSTA participou da elaboração do projeto de pesquisa, da estratégia experimental, da coleta de dados, tabulação, da discussão dos resultados e da redação do artigo. NG MORAIS participou da preparação dos grupos experimentais, da manutenção dos animais no biotério e da coleta de dados. TM ALMEIDA participou da preparação dos grupos experimentais, da manutenção dos animais no biotério e da coleta das amostras. MS SEVERO participou da elaboração do projeto de pesquisa e da estratégia experimental. CMMB CASTRO participou da elaboração do projeto de pesquisa, da tabulação, da discussão dos resultados e da elaboração do artigo.

\section{REFERÊ NCIAS}

1. Gurmini J, Cecílio CAW, Schuler LS, Olandoski M, Noronha L. Desnutrição intra-uterina e suas alterações no intestino delgado de ratos Wistar ao nascimento e após lactação. J Bras Patol Med Lab. 2005; 41(4):271-8.

2. Cunningham-Rundles S, McNeeley DF, Moon A. Mechanisms of nutrient modulation of the immune response. J Allergy Clin Immunol. 2005; 115(6): 1119-28. doi: 10.1016/j.jaci.2005.04.036.

3. Guedes RCA, Melo APR, Teodosio NR. Nutrição adequada: a base do funcionamento cerebral. Cienc Cult. 2004; 56(1):32-5.

4. Melo JF, Macedo EMC, Paes Silva RP, Viana MT, Ferreira e Silva WT, Castro CMMB. Efeito da desnutrição neonatal sobre o recrutamento celular e a atividade oxidante-antioxidante de macrófagos em ratos adultos endotoxêmicos. Rev Nutr. 2008; 21(6):683-94. doi: 10.1590/\$1415-5273200800 0600007.

5. Weglarczyk K, Baran J, Zembala M, Pryjma J. Caspase-8 activation precedes alterations of mitochondrial membrane potential during monocyte apoptosis induced by phagocytosis and killing Staphylococcus aureus. Infec Immun. 2004; 72(5):2590-97. doi: 10.1128/IAl.72.5.2590-2597.2 004. 
6. Zareie M, Singh PK, Irvine EJ, Sherman PM, McKay DM, Perdue MH. Monocyte/macrophage activation by normal bacteria and bacterial products. Implications for altered epithelial function in Crohn's disease. Am J Pathol. 2001; 158 (3):1101-9.

7. Hunter CA, Reiner SL. Cytokines and T cells in host defense. Curr Opin Immunol. 2000; 12(4):413-18. doi: 10.1016/S0952-7915(00)00110-2.

8. Grimble RF. Nutritional modulation of cytokine biology. Nutrition. 1998; 14:(7-8)634-40.

9. Katona P, Katona-Apte J. The interaction between nutrition and infection. Clin Infect Dis. 2008; 46(10):1582-8. doi: 10.1086/587658.

10. Rice AL, Sacco L, Hyder A, Black RE. Malnutrition as an underlying cause of childhood deaths associated with infectious diseases in developing countries. Bull World Health Organ. 2000; 78(10): 1207-21.

11. Kanafani ZA, Fowler VG Jr. Staphylococcus aureus infections: new challenges from an old pathogen. Enferm Infecc Microbiol Clin. 2006; 24(3):182-93.

12. Stevens DL. Community-acquired Staphylococcus aureus infections: increasing virulence and emerging methicillin resistance in the new millennium. Curr Opin Infect Dis. 2003; 16(3):189-91.

13. Salgado MM, Pignatari ACC, Bellinati-Pires R. Phagocytosis and killing of epidemic methicillinresistant Staphylococcus aureus by human neutrophils and monocytes. Braz J Infect Dis. 2004; 8(1):80-9. doi: 10.1590/S1413-867020040001 00005.

14. Hill AD, Naama H, Shou J, Calvano SE, Daly JM. Antimicrobial effects of granulocyte-macrophage colony-stimulating factor in protein-energy malnutrition. Arch Surg. 1995; 130(12):1273-7.

15. Calder PC, Jackson AA. Undernutrition, infection and immune function. Nutr Res Rev. 2000; 13(1): 3-29.

16. Lu YF, McEwan NA. Staphylococcal and micrococcal adherence to canine and feline corneocytes: quantification using a simple adhesion assay. Vet Dermatol. 2007; 18(1):29-35. doi: 10.1111/j.13653164.2007.00567.

17. De Castro CMMB, De Castro RM, Medeiros AF, Santos AQ, Silva WTF, Lima Filho JL. Effect of stress on the production of $\mathrm{O} 2$ - in alveolar macrophages. J Neuroimmunol. 2000; 108(1/2):68-72.

18. Porto SMM S, Viana MT, Silva KM, Diniz MFA, Castro CMMB. Desnutrição neonatal e microbiota normal da cavidade oral em ratos. Rev Nutr. 2007; 20(6):625-32. doi: 10.1590/S1415-52732007000 600005 .
19. Melo JFM, Aloulou N, Duval JL, Vigneron P, Bourgoin L, Leandro CG, et al. Effect of a neonatal low-protein diet on the morphology of myotubes in culture and the expression of key proteins that regulate myogenesis in young and adult rats. Eur J Nutr. 2011; 50(4):243-50. doi: 10.1007/s00394-01 0-0132-9.

20. Souza AS, Pacheco LC, Castro PS, Carmo MGT. Influência da desnutrição promovida pela dieta básica regional sobre o perfil de ácidos graxos do leite materno, o crescimento e o desenvolvimento de ratos jovens. Rev Nutr. 2009; 22(4):467-81. doi: 10.1590/S1415-52732009000400003.

21. Guzmán-Silva MA, Wanderley AR, Macêdo VM, Boaventura GT. Recuperação da desnutrição em ratos mediante rações adicionadas ou não de suplemento alimentar e de vitaminas e minerais durante o período de crescimento. Rev Nutr. 2004; 17(1):59-69. doi: 10.1590/S1415-527320040001 00007.

22. Chaves N. Nutrição básica e aplicada. $2^{\text {a }}$ ed. Rio de Janeiro: Guanabara Koogan; 1985.

23. Kruszyńska E, Białek M, Janicka G, Bugalski R, Belzyt E, Czajkowski $H$, et al. Susceptibility to antibiotics of Staphylococcus aureus strains. Med Dosw Mikrobiol. 1997; 49(3-4):141-4.

24. Cunha WD, Friedler G, Vaisberg M, Egami MI, Costa Rosa LF. Immunosuppression in undernourished rats: the effect of glutamine supplementation. Clin Nutr. 2003; 22(5):453-57.

25. Rodríguez L, González C, Flores L, Jiménez-Zamudio L, Graniel J, Ortiz R. Assessment by flow cytometry of cytokine production in malnourished children. Clin Diagn Lab Immunol. 2005; 12(4):502-7. doi: 10.1128/CDLI.12.4.502-507.2005.

26. Ishikawa LLW, França TGD, Chiuso-Minicucci F, Zorzella-Pezavento SFG, Marra NM, Pereira PCM, et al. Dietary restriction abrogates antibody production induced by a DNA vaccine encoding the mycobacterial $65 \mathrm{kDa}$ heat shock protein. Genet Vaccines Ther. 2009; 7:11. doi: 10.1186/14 79-0556-7-11.

27. Wieringa FT, Dijkhuizen MA, West CE, van der Ven-Jongekrig J, Mihilal and van der Meer JW. Reduced production of immunoregulatory cytokines in vitamin A- and zinc-eficient Indonesian infants. Eur J Clin Nutr. 2004; 58(11):1498-504. doi: 10.103 8/sj.ejcn.1601998.

28. Polack E, Nahmod VE, Emeric-Sauval E, Bello M, Costas $M$, Finkelman $M$, et al. Low lymphocyte interferon gamma production and variable proliferative response in anorexia nervosa patients. J Clin Immunol. 1993; 13(6):445-51. doi: 10.1007/BF 00920020. 
29. Nájera O, Gonzáles C, Toledo G, López L, Ortiz R. Flow cytometry study of lymphocyte subsets in malnourished and well-nourished children with bacterial infections. Clin Diagn Lab Immunol. 2004; 11(3):577-80. doi: 10.1128/CDLI.11.3.577-580.2 004.

30. Fló J, Elías F, Benedetti R, Massouh E. Reversible effects on $B$ and $T$ cells of the gut-associated lymphoid tissues in rats malnourished during suckling: impaired induction of the immune response to intra-Peyer patches immunization with cholera toxin. Clin Immunol Immunopathol. 1996; 80(2):147-54. doi:10.1006/clin.1996.0108.

31. Hughes SM, Amadi B, Mwiya M, Nkamba $H$, Tomkins A, Goldblatt D. Dendritic cell anergy results from endotoxemia in severe malnutrition. J Immunol. 2009; 183(4):2818-26. doi: 10.4049/jimmunol.0 803518.

32. Jakab JG, Warr GA, Astry CL. Alterations of pulmonary defense mechanisms by protein depletion diet. Infect Immun. 1981; 34(2):610-22.

33. Fock RA, Vinolo MAR, Crisma AR, Nakajima K, Rogero MM, Borreli P. Protein-energy malnutrition modifies the production of interleukin-10 in response to lipopolysaccharide (LPS) in a murine model. J Nutr Sci Vitaminol. 2008; 54(5):371-7. doi:10.3177/jnsv.54.371.

34. Duckworth GJ, Jordens JZ. Adherence and survival properties of an epidemic methicillin-resistant strain of Staphylococcus aureus compared with those of methicillin-sensitive strains. J Med Microbiol. 1990; 32(3):195-200. doi: 10.1099/00222615-32-3-195.

35. Coia JE, Browning L, Haines L, Birbeck TH, Platt DJ. Comparison of enterotoxins and haemolysins produced by methicillin-resistant (MRSA) and sensitive (MSSA) Staphylococcus aureus. J Med Microbiol. 1992; 36(3):164-71. doi: 10.1099/002 22615-36-3-164.

36. Schmitz FJ, MacKenzie CR, Geisel R, Wagner S, Idel $\mathrm{H}$, Verhoef J, et al. Enterotoxin and toxic shock syndrome toxin-1 production of methicillin resistant and methicillin sensitive Staphylococcus aureus strains. Eur J Epidemiol. 1997; 13(6):699-708. doi: 10.1023/A:1007357206672.

37. Cosgrove SE, Sakoulas G, Perencevich EN, Schwaber MJ, Karchmer AW, Carmeli Y. Comparison of mortality associated with methicillin-resistant and methicillin-susceptible Staphylococcus aureus bacteremia: a meta-analysis. Clin Infect Dis. 2003; 36(1):53-9. doi: 10.1086/345 476.

38. Mekontso-Dessap A, Kirsch M, Brun-buisson C, Loisance D. Poststernotomy mediastinitis due to Staphylococcus aureus: comparison of methicillinresistant and methicillin-susceptible cases. Clin Infect Dis. 2001; 32(6):877-83. doi: 10.1086/31 9355. 
